\title{
REPRESENTAÇÕES SOBRE O TRABALHO ENTRE CATADORES DE MATERIAL RECICLÁVEL COOPERATIVADOS
}

\author{
SOCIAL REPRESENTATIONS OF WORK AMONG ASSOCIATED URBAN \\ WASTE PICKERS
}

\author{
Sueli Maria Cabral ${ }^{1}$ \\ Marilia Verissimo Veronese ${ }^{2}$
}

\section{RESUMO}

Este artigo analisa as representações sociais sobre o trabalho compartilhadas por catadores de material reciclável associados. Realizada em uma cooperativa de reciclagem, a pesquisa que gerou o texto analisou a articulação entre os diferentes sentidos acerca do trabalho com o lixo e como geram processos de pertencimento social, por meio da intercessão de elementos objetivos e simbólicos produzidos com base no trabalho solidário. Foram realizadas entrevistas com 28 trabalhadores associados a uma cooperativa de reciclagem na região metropolitana de Porto Alegre, RS, Brasil. As entrevistas foram analisadas pelo método do Discurso do Sujeito Coletivo, com proposta de organização de dados qualitativos de natureza verbal e fundamentada na Teoria das Representações Sociais. Evidenciou-se uma rede de relações e sentidos que emergem do contexto de associação/cooperação, fomentando estratégias e ações com potência - na forma de esperança - para combater os problemas em âmbito privado, mas igualmente no aspecto público de suas vidas, entrelaçando-os.

Palavras-chave: trabalho, catadores de material reciclável, representações sociais, discurso do sujeito coletivo.

\begin{abstract}
The article analyzes the social representations of work shared among a group of waste urban pickers. Conducted in a recycling cooperative, the research that generated this text presents an articulation between the different senses produced in the work with garbage and how they generate processes of social belonging, based on the intercession of objective and symbolic elements. The interviews were conducted with twenty-eight associate workers, in the metropolitan region of Porto Alegre, RS, Brazil. The interviews were analyzed using the Collective Subject Discourse method, a proposal for the organization of qualitative verbal data, based on the Theory of Social Representations. A network of relationships that fosters strategies and actions were found, with the power through hope - to fight problems in a private sphere, but also in the public aspect of their lives, intertwining them.
\end{abstract}

Keywords: work, urban waste pickers, social representations, discourse of the collective subject.

\footnotetext{
1 Doutora em Ciências Sociais pela Universidade do Vale dos Sinos (Unisinos). Docente e pesquisadora do Mestrado Acadêmico em Psicologia da Universidade Feevale.

2 Doutora em Psicologia Social pela Pontifícia Universidade Católica do Rio Grande do Sul (PUCRS). Docente e Pesquisadora do Programa de Pós-graduação em Ciências Sociais da UNISINOS - Escola de Humanidades (Bolsista PQ2 do CNPq).
} 


\section{INTRODUÇÃO}

No Brasil, os catadores de material reciclável estão nos cenários urbanos e na literatura desde pelo menos o século XIX e acompanharam praticamente todo o processo de urbanização do país (IPEA, 2017). Esse grupo de pessoas passou a ser um instrumento essencial no projeto de higienização das cidades, pois ao triar o lixo acabava por organizar seus cenários, fazendo de forma privada - e mal remunerada - um trabalho que caberia ao poder público. Essa prática, no entanto, esteve associada a indivíduos pobres, inscritos nos espaços não apenas da precariedade, mas igualmente da invisibilidade social, considerados descartáveis economicamente, incômodos politicamente e perigosos socialmente.

As unidades de reciclagem somente surgem de forma mais organizada no cenário nacional no final dos anos 1980. Já os catadores de recicláveis, apesar do reconhecimento de sua atividade como profissão, status concedido pela aprovação do Projeto de Lei n. ${ }^{\circ}$ 6822/10 e das recentes políticas públicas de infraestrutura e fomento, como a Política Nacional de Resíduos Sólidos (PNRS) e o Programa Pró-Catador, ainda são cidadãos socialmente estigmatizados (SILVA; CARNEIRO, 2015). Conforme Bauman (1999), o estigma impõe determinados lugares para determinadas pessoas, em dada sociedade. $\mathrm{O}$ indivíduo estigmatizado percebe onde "deve" estar e permanecer, em uma dinâmica perversa de produção da desqualificação social (PAUGAM, 2003).

Destaca-se que no Brasil existe mais de um milhão de catadores (MNCR, 2019), embora apenas $13 \%$ dos resíduos urbanos sejam encaminhados para a reciclagem. Nesse processo, 90\% de todo o material que chega a ser reciclado no Brasil passa pelas mãos dos catadores, individuais ou cooperativados (IPEA, 2017). Catadores de material reciclável urbano não são um conjunto populacional homogêneo. Há muita diversidade entre eles em termos de trajetórias de vida, experiências anteriores com o trabalho e idade, sendo que a maioria declara que exerce a atividade por falta de opção. Grande parte do trabalho ainda é realizada por meio de relações de informalidade, e os trabalhadores obtêm baixa remuneração pela venda do material (IPEA, 2017).

Essa atividade acabou por constituir um segmento importante no campo da economia solidária no Brasil, que evoca um amplo espectro de formas organizativas, entidades representativas da sociedade civil e ações de governos. Em artigo publicado recentemente, Gaiger e Kuyven destacam quatro componentes que sintetizariam o campo da economia solidária no Brasil: a) os empreendimentos econômicos solidários (EES), dedicados a atividades econômicas produtivas, a finanças solidárias, ao consumo coletivo, à agroecologia etc; b) as organizações de apoio e fomento, como as ONGs, algumas entidades sindicais, pastorais sociais e incubadoras universitárias; c) os órgãos de representação e articulação política, como os fóruns brasileiro (FBES) e regionais; d) setores do Estado que articulam políticas públicas de economia solidária (GAIGER; KUYVEN, 2020).

Houve uma aproximação entre o cooperativismo/associativismo popular da economia solidária e a atividade de catação de resíduos urbanos. Alguns catadores preferem a catação individual - embora, mesmo nesses casos, não trabalhem completamente sós, sempre contando com familiares ou amigos nas estratégias que desenvolvem - para não ter de cumprir regras e horários, mas muitos encontram maior estabilidade e dignidade justamente entre seus pares e optam por trabalhar associados (VERONESE, 2016; SILVA, 2018). É com esses sujeitos que pesquisamos (e não sobre eles). O relato dessa experiência de pesquisa está sintetizado neste artigo.

O objetivo do trabalho que embasa o texto é analisar as representações sociais sobre o trabalho construídas por um grupo de catadores cooperativados, que se reconhecem como 
parte integrante do campo da economia solidária, sujeitos que convivem com o lixo diariamente por meio de elementos que se unem em uma lógica - situada no cotidiano - que promove a fusão grupal, possibilitando a conjunção entre o reconhecimento e a esperança. Tal fusão é possibilitada por uma dinâmica associativa e solidária, como ficará claro ao longo desta análise.

Para refletir sobre as representações, foi necessário compreendê-las com base em uma experiência comum de sujeitos trabalhadores associados, por meio de um olhar que concebesse o fenômeno como complexo não apenas em sua definição, mas em sua constituição dinâmica. Um tecido formado por diferentes fios que se entrelaçaram em uma coisa só, não destruindo a diversidade que o teceu.

Passa-se, então, a apresentar os resultados de pesquisa que versou sobre as representações sociais construídas por trabalhadores que cotidianamente trabalham com resíduos sólidos em um município da região metropolitana de Porto Alegre, um estudo que revela o acontecer cotidiano como uma instância de alianças, que influenciam e são influenciadas pelas interações sociais. Estas propiciam a construção de uma sociabilidade que, balizada por um estar-junto, confere sentidos às coisas e às pessoas em volta. Os dados foram coletados entre os anos de 2015 e 2017, em uma cooperativa de catadores da região metropolitana de Porto Alegre.

Inicialmente, será apresentada uma discussão sobre a precariedade do trabalho experimentada pelos sujeitos desta pesquisa em suas experiências pregressas.

\section{O TRABALHO COMO UMA QUESTÃO SOCIAL}

O convívio com o desemprego, a pobreza, a violência, a supressão de direitos, a discriminação e a criminalidade, entre outras mazelas, acaba por moldar uma forma de estar no mundo; uma das questões sociais mais pungentes se refere ao universo do trabalho e suas interfaces. Destacam-se nesse cenário o desemprego estrutural e o trabalho em condições precárias, com consequências no âmbito geral da vida em sociedade.

Belfiori-Wanderley (apud Castel, 2011) afirma que a questão social adquire um conteúdo especial na multidimensionalidade dos processos e das estruturas sociais e na forma pela qual os sujeitos são produtores dos e produzidos pelos mesmos. O autor ainda afirma:

Eu diria que a questão social significa, desde logo, saber quem estabelece a coesão e em que condições ela se dá numa determinada sociedade. Como é sabido, no caso latino-americano, ela foi imposta pelos colonizadores por meio do pacto colonial, e segue dirigida pelo pacto de dominação burguesa (apud Castel, 2011, p. 60).

Pensar a questão social é evocar uma inteligibilidade altamente incerta e, por vezes, volátil, em um mundo no qual se torna necessário considerar alguns elementos essenciais, como o processo de internacionalização da economia associado a períodos de hegemonia neoliberal e os Programas de Transferência de Renda e seus resultados na redução da extrema pobreza. Essa combinação não foi capaz de desconstituir os processos de produção de uma subumanidade contemporânea, por meio do ajustamento à pobreza e do fomento de "cidades" criadas pelas e para as elites, como o Alphaville em São Paulo, e a Barra da Tijuca, no Rio de Janeiro (FREITAG, 2007). Há, portanto, uma pobreza ajustada que organiza outra cidade, dando-lhe suporte de diversos serviços - lícitos ou não.

Entende-se aqui como ajustamento à pobreza a situação vivida por aqueles que permanecem vulneráveis nas estruturas sociais, os sujeitos pobres que permeiam uma zona intermediária, compartilhando o mesmo universo espacial e temporal, mas pouco interagindo 
de fato e de direito com os "outros", os membros menos vulneráveis da sociedade, a não ser no registro das desigualdades de poder.

Pensar a pobreza como um importante elemento de inteligibilidade sobre o trabalho como questão social é compreendê-la como um fenômeno multifacetado: histórico, social, político e cultural que, no processo, traduz igualmente quem é o pobre. De acordo com Wanderley (2011), os pobres são um grupo não apenas destituído de riquezas materiais, mas também de poder, de trabalho e de informação relevante. Portanto, considerando-se o processo brasileiro de desenvolvimento das últimas décadas, a pobreza vem produzindo um novo tipo de vulnerabilidade, marcada pela formação de grupos sociais considerados desnecessários, descartáveis.

Cabe destacar que para Castel a questão social se caracteriza por "uma inquietação quanto à capacidade de manter a coesão de uma sociedade. A ameaça de ruptura é apresentada por grupos cuja existência abala a coesão do conjunto" (2003, p. 41). As considerações do autor partem da identificação de uma correlação profunda entre o lugar ocupado pelo sujeito na divisão social do trabalho e sua participação nas redes de sociabilidade e nos sistemas de proteção.

A diferença entre a questão social da fase do capitalismo industrial em relação à anterior diz respeito ao surgimento de novos atores e novos conflitos, pois a questão social torna-se a "questão" de um lugar ocupado pelos contingentes menos integrados (populações flutuantes, miseráveis, não socializadas, cortadas de seus vínculos) na sociedade industrial. A fragilidade e a flexibilidade dos direitos sociais e suas regulações e proteções ligadas ao trabalho promovem processos de exclusão, que acabaram por se tornar, na última década, a questão social por excelência. Castel (2003) adverte, contudo, que há duas armadilhas básicas no entendimento e no uso do termo: o caráter analítico (reflexão) e o técnico (ação). O lócus analítico baliza como um ardil a eleição da exclusão como problema social, na medida em que essa abordagem autonomiza situações-limite que só têm sentido quando colocadas em um processo, ou seja, quando, mais do que descrever os estados de despossuir, reconstroem um continuum que liga os in's e os out's.

Quanto ao caráter mais técnico (ação), o autor alerta para o uso da noção de exclusão no âmbito das políticas públicas. Há, assim, uma permissão para que a exclusão seja tratada fora do campo político e inserida no campo da técnica, por meio de especialistas que atacam os problemas, corroborando a ideia de que os problemas sociais são como adendos de uma hegemonia das leis econômicas e dos ditames do capital financeiro, renunciando à intervenção sobre o processo que produz tais situações.

Quanto à coesão social, delineada pela marginalidade e pela vulnerabilidade social, situações marginais são fruto da precarização do trabalho e da fragilidade dos suportes relacionais. $\mathrm{O}$ autor aprofunda sua análise por meio de um modelo teórico que explicita esse conjunto em basicamente três grupos (zonas), partindo de uma correlação profunda entre o lugar ocupado pelo sujeito na divisão social do trabalho e sua participação nas redes de sociabilidade e nos sistemas de proteção. Em síntese, podem-se explicitar tais gradações da seguinte forma:

a) Zona de Integração: corresponde à coesão social com trabalho estável e à inserção relacional sólida. Segundo Castel, "Esses grupos gozam de segurança no emprego e integram fortes e coerentes redes de dependência. Eles podem ser pobres, todavia como sugerido não suscitam problemas, salvo se eles se desligassem, passando para a zona da vulnerabilidade" (1997, p. 23).

b) Zona de Vulnerabilidade ou Zona Intermediária: correspondente a uma já instalada vulnerabilidade social, que conjuga trabalho precário e fragilidade dos suportes de 
proteção. Quem a ocupa está constantemente ameaçado a passar para a terceira zona.

c) Zona de Desfiliação: condição de sujeito que está em um "espaço" no qual há ausência de participação produtiva e isolamento relacional. Para Castel (1997), ele não trabalha, formalmente falando, apesar de poder trabalhar, no sentido de estar apto ao trabalho. Ao mesmo tempo, ele está cortado de todo apoio relacional. É o errante, o morador de rua, o estrangeiro que não pode ser reconhecido por ninguém e se encontra rejeitado, de fato, por toda parte. Consequentemente, sobre ele recaem medidas repressivas cruéis, do rechaço à exposição à morte, em casos extremos.

Cabe, contudo, uma ressalva quanto ao conceito da Zona de Desfiliação. Os sujeitos inseridos nesse grupo não estão necessariamente sem trabalho. Há de se considerar que, para Castel, a precarização do emprego e o aumento do desemprego manifestam um déficit de lugares ocupáveis na estrutura social, não havendo uma utilidade social e um reconhecimento público. O autor esclarece:

\footnotetext{
Igualmente, o que chamei de desfiliação poderia ser trabalhado para mostrar que não equivale necessariamente a uma ausência completa de vínculos, mas também à ausência de inscrição do sujeito em estruturas portadoras de um sentido. Hipótese de novas sociabilidades flutuantes que não se inscrevem mais em disputas coletivas, andanças imóveis de que a falta de objetivos precisos dos jovens desocupados propõe uma ilustração (2003, p. 536).
}

Nesse sentido, o termo desfiliação (neologismo derivado do termo francês desfilié) é o que mais concebe uma ruptura de certos lócus de pertencimento e de certos vínculos societais, cuja trajetória é feita por uma série de protrusões, e não apenas em relação a sua situação no mundo do trabalho. Dessa forma, Castel (1997, 2003, apud LANCETTI, 1994) prefere o termo desfiliação em lugar de exclusão, uma vez que o primeiro termo permite a percepção clara da vulnerabilidade e de suas implicações em um processo de inexistência social.

Assim, enquanto no eixo do trabalho - como descrito anteriormente - pode existir integração, precarização e exclusão, no eixo relacional podem ocorrer diferentes formas de inserções que se inscrevem entre dois pontos: a inscrição sólida em uma rede de sociabilidade e o isolamento social total. Os diferentes cruzamentos desses vetores acabam por produzir zonas diferentes do espaço social.

Há de se fazer um destaque, portanto, ao uso dessa categoria - desfiliação - no presente estudo. $\mathrm{O}$ grupo pesquisado, em sua totalidade, já esteve de alguma forma inserido na zona denominada por Castel de intermediária, com diferentes inclusões de sociabilidade sociofamiliar; contudo, pelas contingências vividas, entrou em um processo de desfiliação e, portanto, de flutuação na estrutura social.

\section{Sobre o trabalho precário}

Segundo o IBGE, já no início de 2020 percebia-se uma perda significativa do poder de compra, uma queda acentuada da população ocupada e do trabalho com carteira assinada e uma situação de estagnação, em que nem mesmo o mercado informal está conseguindo absorver os trabalhadores que perderam o emprego, ou seja, a informalidade aliada à precariedade tem se tornado um elemento muito presente no cotidiano de vários trabalhadores brasileiros.

Nos últimos anos, em especial a partir de 2015, houve uma metamorfose da precarização, fruto dos processos históricos, presentes em todas as regiões do Brasil, em todos 
os tipos e ramos setoriais (formal, informal, autônomo e rural) e na vida dos trabalhadores mais ou menos qualificados. Há, portanto, uma institucionalização da precarização nas relações de trabalho, trazendo ou solidificando a insegurança e a volatilidade dos vínculos, infringindo, com isso, perdas significativas de direitos, de emprego e de qualidade de vida para todos que vivem do trabalho.

Considerando os estudos de Druck (apud ANTUNES, 2013), é possível sintetizar a precarização do mercado de trabalho em cinco grandes grupos:

1. Vulnerabilidade das formas de inserção e desigualdades: presente em função de um mercado heterogêneo, segmentado e desigual, em que há uma procura maior que a oferta de postos de trabalho e uma vulnerabilidade marcante nas formas de inserção (informal, precário, autônomo, rural e até alguns modos de inserção formais urbanos).

2. Intensificação do trabalho e terceirização: encontrada nos padrões de gestão e organização do trabalho, fruto de condições precárias, em um processo constante por meio da intensificação do trabalho (imposição de metas inalcançáveis, extensão da jornada de trabalho, polivalência etc.), alimentada por uma gestão do (e pelo) medo e de abuso de poder, na discriminação criada pela terceirização.

3. Insegurança e saúde no trabalho: referem-se às condições de instabilidade, insegurança e agravos à saúde no trabalho, não prevenidos e não tratados/reparados.

4. Perda das identidades individual e coletiva: relacionada às condições de desemprego (aberto ou oculto pelo trabalho precário) ou à ameaça constante da perda do emprego, que tem se constituído como uma eficiente estratégia de dominação no âmbito do trabalho. Trata-se de uma precarização simbólica e real, que resulta em desfiliação ou sentimento de inúteis para o mundo.

5. Fragilização da organização dos trabalhadores: pode ser identificada nas dificuldades da organização sindical e das demais formas de representação dos trabalhadores.

Essa nova precarização, típica do predomínio de políticas neoliberais que se consubstancia pelos cinco fatores anteriormente descritos, resume o crescente processo de degradação a que vários trabalhadores são submetidos, as estratégias da "gestão do medo", a depreciação e a desvalorização e, em muitos casos, as péssimas e desumanas condições de trabalho que fomentam a perversão da vida de muitos trabalhadores (SOUZA, 2017).

Trata-se de "uma precarização que atinge a todos indiscriminadamente e cujas formas de manifestação diferem em grau de intensidade, mas tem como unidade o sentido de ser ou estar precário numa condição não mais provisória, mas permanente" (DRUCK apud ANTUNES, 2013 , p. 56). Cabe recordar que tudo pode agudizar-se tragicamente durante crises econômicas, como no caso do Brasil pós-2015, quando não se conseguiu mais sustentar as benesses que os altos preços das commodities brasileiras financiaram, em termos de políticas públicas de combate à pobreza (OLIVEIRA; VERONESE, 2019).

Nesse sentido, apesar das clivagens, as relações de trabalho ainda permitem compreender importantes facetas da construção social contemporânea, o que o torna possível de ser compreendido como uma referência que media o individual e o coletivo. 


\section{A economia solidária e sua diversidade}

A economia solidária se apresentou, desde a crise econômica dos anos 1980, como uma importante forma de acolher sujeitos empobrecidos em situação de precariedade laboral. Há uma diversidade de aspirações que estão na base da constituição das experiências de economia solidária, ao sul e ao norte do mundo. Tanto fatores negativos como positivos atuam para produzir uma racionalidade cooperativa, autogestionária e um desejo de adesão; não é somente a pobreza, o sofrimento e a precariedade que fazem surgir um Empreendimento Econômico Solidário (EES). Esses sentimentos de falta podem desembocar em outras soluções, como busca de emprego formal, desalento e adesão à criminalidade. Contudo, uma vez que estejam presentes também fatores positivos, como aspiração a uma vida melhor, desejo de agregação e associação e racionalidade projetiva, por vezes pautada em lutas políticas históricas, como no caso das associações de catadores, o associativismo popular se tornar uma opção atrativa. (GAIGER, 2014).

As experiências que se disseminaram em zonas rurais empobrecidas e em periferias urbanas a partir dos anos 1980 levaram à eclosão do fenômeno dos catadores urbanos organizados nas grandes e médias cidades brasileiras. Desde os anos 1970, trabalhadores sem oportunidades, instados pela incapacidade de absorção pelo mercado formal de trabalho e pela falta de instrumentos para inserir-se estavelmente na economia formal foram compelidos a sobreviver de trabalhos por conta própria e de ocupações temporárias informais. (VERONESE; GAIGER; FERRARINI, 2017).

Durante a redemocratização do país, na década de 1980, houve um processo de reconstrução da sociedade civil, por meio dos movimentos sociais, ocasionando forte discussão na esfera pública e a (re)emergência de lutas por novas políticas públicas, fazendo avançar a cultura democrática, em busca da ampliação da cidadania e do acesso a direitos sociais. $\mathrm{O}$ processo político, contudo, não é acompanhado por condições objetivas, de ordem econômica; ao mesmo tempo, a precarização do trabalho avança globalmente e atinge o país de forma contundente. Estes dois fatores combinados, redemocratização e precarização do trabalho, foram em parte o caldo de cultura para a eclosão de inúmeros empreendimentos solidários, mediados pelo apoio de entidades como pastorais sociais, Cáritas e outros movimentos sociais que ressurgiam na cena nacional (LACERDA, 2013).

Nesse contexto, surgiram iniciativas associativas comunitárias de trabalho e geração de renda, crescendo progressivamente em número e segmentos, originando o conceito de empreendimento econômico solidário, já em meados dos anos 1990 (GAIGER, 2014). Até hoje, acredita-se que esse conceito não foi totalmente compreendido tal como pensado: um conceito de tipo-ideal weberiano. A descrição de um EES pleno de autogestão, horizontalidade, cooperação, entreajuda, cuidados ambientais, educação cooperativa continuada, inserção comunitária significativa e geração de renda suficiente, tal como o tipo-ideal de Max Weber, não se encontra na realidade empírica; alguns chegam mais perto, enquanto outros se distanciam muito. Entretanto, o construto serve para comparar a realidade empírica com as características do "tipo puro", tendo antes de mais nada um valor heurístico, de análise. Foi inapropriadamente criticado como distante da realidade concreta, talvez por quem não compreendeu seu alcance teórico; houve quem confundisse o tipo-ideal com a realidade social. A imensa pluralidade dos empreendimentos reais não se confunde com o construto sociológico, e muito menos com idealizações românticas ou prescrições normativas. 
Na busca da associação entre iguais em vez do contrato entre desiguais, a diversidade é a chave definidora dos empreendimentos resultantes. O objetivo do empreendimento solidário é a maximização do bem-estar para os participantes, distanciando-se da busca da maximização do lucro, tipicamente capitalista. Os excedentes, quando conquistados, têm sua destinação decidida pelos trabalhadores em âmbito coletivo, pois a propriedade compartilhada dos meios e da gestão do trabalho é característica do empreendimento solidário cooperativo, associativo ou comunitário. Tais critérios não são encontrados de forma absoluta nos empreendimentos, como já argumentado anteriormente, existindo diversos graus de apropriação dos mesmos, bem como de práticas autogestionárias frágeis ou já mais avançadas (VERONESE; SCHOLZ, 2014).

\section{Catação de resíduo urbano: da precariedade à solidariedade}

Historicamente, a atividade de catação é realizada por meio de relações trabalhistas informais, sem registro oficial, o que muitas vezes impede o acesso dos catadores a direitos trabalhistas garantidos em lei. Há de se destacar que a prática de lidar com o lixo sempre esteve de alguma forma ligada àqueles considerados "socialmente inferiores". Segundo Alain Corbin,

os reformadores projetam evacuar, ao mesmo tempo que o lixo, o vagabundo, os fedores da imundície e da infecção social [...]. Os forçados "arrastam todas as manhãs, pelas ruas [...], grandes carroças de quatro rodas por um timão ao qual se acham acorrentados; correntes mais longas e mais leves mantêm ligadas às mesmas carroças mulheres condenadas pela justiça [...] uma metade dessas mulheres varre as ruas, enquanto a outra metade enche a carroça com as imundícies [...] (1987, p. 123).

Nesse sentido, pobres, velhos, mendigos, homossexuais, judeus e doentes tornaram-se responsáveis pela desodorização dos espaços públicos (remoção de lixo, dejetos e cadáveres), sendo estigmatizados e, portanto, constituídos socialmente por representações sociais que os igualavam ao lixo, ao mau cheiro; estes como indicativos da origem do sujeito, de seus lócus de pertencimento e de permanência, o que os associava à repulsa, ao medo de infecção e à própria prática da intolerância.

A proximidade dos catadores com o lixo, muito embora hoje a catação seja uma profissão constante no Código Brasileiro de Ocupações, ainda cria uma representação que pode envolver sentimentos de piedade pela suposta miserabilidade do catador; contudo, Eigenheer observa que o que existe, para grande parte das pessoas, é o sentido de repulsa, "a putrefação da matéria orgânica no entorno, a sujeira das roupas e o mau aspecto das pessoas que ali trabalham é que parecem ser insuportáveis" (2003, p. 157).

Assim, se o lixo funciona com base em uma dimensão simbólica, as pessoas que com ele trabalham assim funcionam também. Como seres sociais, compactuamos com um conjunto de normas e valores, inclusive sobre higiene e sobre lixo; aprendemos que a ordem é a limpeza, esta um efeito colateral da construção da ordem (Bauman, 2005), enquanto a desordem é o lixo. Esta inscreve nos corpos daqueles que estão diretamente ligados ao lixo uma quantidade de características que não estão ligadas ao que são efetivamente, mas a como são percebidos, como seus corpos são lidos e representados no senso comum.

Assim, as experiências vividas pelos sujeitos da pesquisa, que estão diretamente ligados ao processo de lixeirização $\mathrm{o}^{3}$, possibilitam um recorte analítico das possíveis dimensões que o trabalho pode assumir, um recorte que não exclui a discriminação, a miséria e a violência,

\footnotetext{
3 Segundo Alvarez (2012), a chamada "lixeirização" se estende dos materiais às pessoas. Os mendigos ficam estigmatizados como sujos, doentes e transmissores de doenças. No entanto, essa caracterização é independente de qualquer processo biológico, mas procede do desenvolvimento da construção social do lixo.
} 
mas que busca compreender, em um campo fortuito de experimentação social, a relação entre seres, saberes e vínculos.

Contudo, nem tudo é desolação nesse campo, que também tem significativa importância e impacto positivo na vida de muitos trabalhadores empobrecidos. A possibilidade de integrarse a um empreendimento e gerar renda, além de conquistar novas formas de sociabilidade, aprendizagens e ação social, está colocada aos catadores e catadoras que entrevistamos, nessa e em outras pesquisas anteriores (VERONESE, SCHOLZ, 2014; CABRAL, 2015; VERONESE, 2016; SILVA, 2018). Quando organizados, vinculados a lutas e movimentos sociais como o Movimento Nacional de Catadores de Material Reciclável (MNCR), eles encontram possibilidades de promoção de justiça socioambiental (SEN, 2000).

No II Mapeamento Nacional da Economia Solidária, realizado pela SENAES, foram mapeados 591 EES desse setor, sendo que, dessa amostra, a maior parte dos grupos encontra-se ainda na informalidade (40,3\%), seguida pela forma de associação $(31,3 \%)$ e de cooperativa (28,3\%). A atividade profissional desempenhada nos EES de reciclagem é apontada como a principal fonte de renda dos sócios em 84,1\% deles. (SILVA; CARNEIRO, 2015).

Eles são a chamada "base da pirâmide" da cadeia produtiva da reciclagem, constituindo a parte mais frágil, pois ficam sujeitos à ação dos atravessadores e das indústrias, que determinam os preços, o volume e as condições dos materiais que serão adquiridos (IPEA, 2013). A politização de parte dos catadores foi determinante para a criação do MNCR, para fazer frente a essas e a outras dificuldades. A consciência da opressão estrutural e o desejo de evitar a dependência de estruturas governamentais e/ou empresariais faz com que o movimento seja um dos indícios de capacidade de produzir processos de mudança de suas condições de vida, inserindo-se em um contexto de participação política e acesso a políticas públicas de fomento (VERONESE, 2016).

Incorporar-se aos coletivos da economia solidária traz vantagens tangíveis aos trabalhadores. Ao trabalharem em conjunto, eles conseguem ter maior poder de barganha com os intermediários que compram seu material, negociando maiores quantidades e variedades. Além disso, conseguem melhor infraestrutura (como a construção de galpões) e maquinário (prensas, veículos) para melhorar as condições de trabalho, o que, individualmente, não seria possível (IPEA, 2013).

\section{METODOLOGIA: IMERSÃO ETNOGRÁFICA E O MÉTODO DO DISCURSO DO SUJEITO COLETIVO}

Optou-se por uma abordagem qualitativa, uma vez que, sob essa perspectiva, é possível compreender de forma singular as atitudes, os comportamentos, as representações circulantes e os atributos do contexto pesquisado, avaliando aspectos emocionais e intencionais, implícitos nos discursos dos sujeitos da pesquisa, dada a característica do objeto de estudo. Entendeu-se, igualmente, ser necessário fazer uso dos pressupostos da etnografia como uma possibilidade de desvelar as representações próprias ao campo, o que exige do observador ir além dos discursos e observar os rituais (formais ou não) do grupo analisado. Para construir a técnica do DSC, os autores Lefévre; Lefévre; Teixeira, (2000) se basearam em Serge Moscovici, que, sobre as representações sociais como um processo ativo, afirmava: “[...] pessoas e grupos, longe de serem receptores passivos, pensam por si mesmos, produzem e comunicam incessantemente suas próprias e específicas representações e soluções às questões que eles mesmos colocam" (2009, p. 45). 


\section{Campo de investigação e participantes}

A presente pesquisa foi desenvolvida em uma cooperativa de reciclagem da região metropolitana de Porto Alegre-RS. Do total de 34 cooperativados do empreendimento, participaram do estudo 28 indivíduos, embora tenham sido consideradas/analisadas 24 entrevistas, em função dos critérios definidos: a) assinatura do termo de consentimento livre e esclarecido e b) estarem na cooperativa por um período não inferior a seis meses. As idades dos informantes variaram entre 21 anos a 62 anos, com média de 34 anos.

\section{Procedimentos de coleta de dados}

Foram utilizadas as técnicas de entrevista semiestruturada e observação participante, com preenchimento de diário de campo por parte das pesquisadoras. O tópico-guia da entrevista (BAUER; GASKELL, 2002) foi elaborado previamente, tendo como pontos de partida os objetivos da pesquisa e a literatura revisada sobre a temática. Realizou-se um estudo-piloto com o intuito de verificar a boa adequação dos instrumentos, verificando-se a validade semântica deles, e em seguida efetuou-se o estudo propriamente dito.

\section{Análise dos dados}

As entrevistas foram analisadas com base no método do Discurso do Sujeito Coletivo (DSC), que é uma proposta de organização e tabulação de dados qualitativos de natureza verbal, obtidos de depoimentos/entrevistas, com fundamento na teoria das representações sociais de Serge Moscovici (2009) e seus pressupostos psicossociais.

Para este autor,

representações sociais são entidades quase tangíveis. Elas circulam, se entrecruzam e se cristalizam continuamente, através duma palavra, dum gesto, ou duma reunião, em nosso mundo cotidiano. Elas impregnam a maioria de nossas relações estabelecidas, os objetos que produzimos e consumimos e as comunicações que estabelecemos (2009, p. 10).

Quanto ao Discurso do Sujeito Coletivo (DSC), trata-se de uma técnica cujo ponto de partida são os depoimentos coletados nas entrevistas que "visa expressar o pensamento de uma coletividade, como se esta coletividade fosse o emissor de um discurso" (LEFEVRE, CRESTANA; CORNETTA, 2003, p. 70).

O DSC tem os depoimentos como matéria-prima, sob a forma de um ou vários discursos-síntese escritos na primeira pessoa do singular, expediente que visa expressar o pensamento de uma coletividade, cujo discurso mantém preservada a diversidade de conteúdo do corpus de dados. A proposta consiste essencialmente em analisar os depoimentos coletados e, posteriormente, interconectá-los com a fundamentação teórica desenvolvida. Trata-se de uma abordagem socioantropológica, porque assim é possível compreender as representações sociais como expressão de referências de uma coletividade na qual os sujeitos em interação se comunicam e produzem sentidos sobre si e o mundo.

De acordo com seus criadores, o Discurso do Sujeito Coletivo apresenta figuras metodológicas centrais, a saber: expressões-chave, ideias centrais e ancoragem.

Expressões-chave (ECH) são trechos do discurso que acabam por revelar o essencial do conteúdo das representações ou das teorias subjacentes a elas. As expressões são parte central da análise e constituem os recortes do discurso. 
Ideias Centrais (IC) são a descrição sintética do sentido das palavras do entrevistado, mas não constituem uma interpretação, e sim uma descrição, revelando o que foi dito.

No que diz respeito à Ancoragem, segundo os autores, algumas ECH não remetem a uma IC, mas à manifestação de uma teoria, ideologia ou crença em que os entrevistados acreditam ou que professam. Trata-se de uma afirmação genérica do enunciador do discurso para enquadrar uma situação específica. Ressalta-se que todo discurso tem uma ancoragem, pois traz uma ideia básica que sustenta o discurso, os valores que estão embutidos na fala, o que está subjacente ao cotidiano.

Do ponto de vista operacional, inicialmente, para extrair as ECHs de cada discurso analisado, foi realizada uma leitura cuidadosa do material e, em seguida, sublinhado o que era relevante, ou seja, a essência do pensamento de cada sujeito social, retratado em seu discurso tal como ela aparecia. A cada ECH identificada foi extraída a IC correspondente. O passo seguinte foi o agrupamento das ICs semelhantes e, para cada agrupamento, nomeou-se uma única IC que se chamou de categoria. Para a construção do DSC reuniram-se as ECHs das ICs enquadradas em cada categoria. Assim, o DSC é um discurso-síntese, composto pela "colagem" das ECHs que têm a mesma IC, e é redigido na primeira pessoa do singular como se uma única pessoa estivesse falando.

Da análise dos dados emergiram dois DSCs que tratavam especificamente das questões sobre trabalho. Nesse sentido, o resultado final trata de uma compilação das Expressões-chaves (ECH) e Ideias Centrais (IC), que foram agrupadas em duas categorias: a) trabalho com o lixo: uma estação possível e b) Trabalho com o lixo: esperança e pertencimento social. A Ancoragem correspondente foi Trabalho, meio de vivência e sobrevivência.

\section{RESULTADOS E DISCUSSÃO}

\section{Categoria 1: Trabalho com o lixo: uma estação possível}

Apesar dos avanços nas últimas décadas, os catadores ainda constituem um exército de invisíveis e, como define Boaventura de Sousa Santos (2007), são produzidos como inexistentes em função de uma vida estigmatizada, desqualificada, sendo sujeitos que se caracterizam pelas ausências, rupturas e fissuras no tecido social.

De acordo com o autor, o pensamento moderno ocidental é abissal e consiste em um sistema de distinções visíveis e invisíveis que são delimitadas por uma linha imaginária. De um lado da linha, está a realidade visível; do outro lado, a realidade traduz-se como inexistente (pela extrema desqualificação social), o que forma dois universos distintos.

Assim, a divisão da realidade social ocorre em dois universos diferentes, o lado de cá e o lado de lá da linha. Essa divisão acaba transformando a realidade do lado de lá, isto é, do outro lado da linha (os pobres, os desvalidos), em algo inconcebível como realidade para o lado de cá da linha (os incluídos e privilegiados). Assim, parte da sociedade trata como irrelevante e incompreensível o lado de lá, na medida em que este é alheio à existência de "outros não iguais a mim"; dessa forma, para alguns grupos sociais, consequentemente, o lado de lá é inexistente - ou irrelevante.

Essa teorização nos auxiliou a compreender nosso campo empírico, uma cooperativa de reciclagem que abrigava pessoas pobres, algumas vindas de períodos recentes de encarceramento, de falta de moradia ou de remuneração suficiente para comer; enfim, de sofrimentos vários. Por meio do grupo que formaram na prática do trabalho associado, e com a mediação de lideranças 
comunitárias hábeis e agregadoras, um sentido especial começou a ser produzido no trabalho de coleta, triagem, enfardamento e comercialização dos resíduos urbanos. Uma alquimia se produziu nos sujeitos (VERONESE, 2016), que ao transformarem o lixo em renda e esperança de dias melhores, reciclaram-se a si mesmos por meio de um processo de ressignificação da autopercepção.

As experiências sofridas, que poderiam construir um ambiente apenas dividido e contraditório, acabaram gestando, quando compartilhadas, uma condição de pertencimento. Relatavam nas entrevistas fazer parte de algo maior e melhor e percebemos que, com isso, certa dignidade foi (re)conquistada (ADICHIE, 2009). É evidente que não se esboça, nesse momento, um cenário romanceado, sem conflitos ou contradições. Descontentamentos coexistem com alguns silêncios e silenciamentos, que são fontes potenciais do inesperado e do imprevisível. Trata-se, inclusive, de um espaço de trabalho tenso, pela amplitude das experiências individuais que se relacionam e que lá circulam diariamente, diante das demandas práticas da realização do trabalho. Há que agir sobre o lixo, coletando-o, beneficiando-o, transformando-o em material que vale dinheiro e garante renda para todos (que ficava um pouco acima de um salário mínimo nacional, no momento da pesquisa).

Inicialmente, destaca-se que o trabalho realizado pelos sujeitos se configura como uma referência possível que media o individual e o coletivo, um elo que pode culminar em integração e identificação entre os participantes. Giddens (2012) comenta sobre os sentidos do trabalho, conceituando-o como algo que, para a maioria dos atores sociais, ocupa um espaço amplo da vida, talvez mais do que qualquer outro tipo de atividade.

É no cotidiano do trabalho que a lógica do pertencimento, ligada à necessidade de sobrevivência, revela-se como um lócus de investigação. A cooperativa tornou-se, para o grupo, um espaço de trabalho que medeia um processo de interação social e permite a construção e a vivência de um sentimento de pertencer a algo, engendrado por meio da apropriação e da partilha dos sentidos. Dessa forma, o local de trabalho composto por coisas e pessoas consubstancia um sentido de pertencimento que só é possível em virtude de uma territorialidade simbólica, manifestada nas ações executadas pela proximidade.

Na leitura atenta do DSC, conceitos de dignidade, orgulho, igualdade e a própria noção de recomeço estiveram presentes. Nessa perspectiva, a palavra trabalho adquire um sentido maior do que a denominação da atividade exercida. Ele ultrapassa a palavra e a coisa a que se refere, e acaba ajudando a entender a pessoa, que se atualiza cultural e profissionalmente, não apenas por meio do manuseio dos resíduos, mas por pertencer ao grupo e aprender no coletivo.

Está presente um princípio de solidariedade, vivenciado pelo domínio de noções éticas e estéticas, construídas especificamente pelo coletivo autogestionário - tais como o silêncio, o respeito, a compreensão e a não cobrança em momentos difíceis. É visível que as relações estabelecidas são constituídas por uma solidariedade que agrega os sujeitos não apenas pela sobrevivência material. Trata-se de uma solidariedade generosa, talvez causadora de estranheza para quem permaneça na superfície, mas que imprime uma marca ao grupo: o compromisso de proteção com o outro.

Eu era ajudante de produção na empresa de esteira e depois fui ajudante de servente de obra $[. .$.$] . De repente, ele ficou doente, não pôde trabalhar e eu tive que ajudar na$ renda da casa. Eu fiquei 10 anos sem trabalhar, casada 10 anos sem trabalhar. Tive que ajudar na renda da casa, porque ele ficou doente e eu não tinha como resolver a demanda dentro de casa, faltava dinheiro. Aí eu vim trabalhar no lixo. As pessoas que estavam trabalhando na associação eram minhas conhecidas, na verdade, meio 
parente. [...]. Eu não iria conseguir trabalhar numa firma de novo. Sem estudo. Não dá, né? Hoje trabalhar aqui significa a minha vida, mas antes era apenas a minha sobrevivência.

Eu vim por necessidade, eu vim porque estava passando fome. Era minha última opção. Antes eu trabalhei como assalariada, mas foi por pouco tempo e eu sabia que eu não iria conseguir de novo. Não tenho estudo, não tenho profissão e eu não me esforcei para ter uma. Eu não ia conseguir novamente o trabalho, nem sem nem com carteira, numa firma [...]. Depois eu fui convidada para trabalhar aqui, porque eu estava no fundo do poço, sem opção, sem esperança, sem nada. Então eu voltei a trabalhar aqui, eu fui salvo pelo lixo.

Os entrevistados, formalmente ou não, já estiveram ligados ao trabalho assalariado, seja no âmbito fabril, seja no doméstico; contudo, a baixa escolaridade, os antecedentes criminais e, em alguns casos, o preconceito social e práticas discriminatórias contra as pessoas gays, lésbicas, travestis e transexuais favoreceram a entrada dos sujeitos na cooperativa. Sua permanência na atividade - ainda que repleta de dignidade, mas carregada de estigmas - justifica-se pelo fato de que eles não acreditam existir para eles uma opção real de trabalho com uma carga menos penosa, física e emocional.

Isso corrobora as ideias de Castel (2003) quando este afirma que os sujeitos na condição de desfiliação são impelidos a viver em uma situação de flutuação na estrutura social, pois não conseguem um lugar estável no mundo do trabalho e no pertencimento comunitário, são supérfluos, "supranumerários", inúteis para o mundo e desfiliados, sem força de pressão. Para o autor, as transformações do mundo do trabalho resultaram em um processo de exclusão e vulnerabilidade, decorrência não apenas de uma constante ausência ou estado de faltas (alimentação, moradia, saúde, educação etc.), mas igualmente do efeito de dois vetores: a) eixo da integração ou não integração pelo trabalho; b) eixo da inserção ou não inserção em uma sociabilidade sociofamiliar.

Eu gosto da cooperativa C., é minha segunda casa, aqui é como uma família, as vezes eu vou embora depois das 7 da noite. Eu tava desempregado, só fazendo "biquinho" e agora eu tô trabalhando aqui e aprendendo. Eu aprendo muito na C., eu não sabia nada sobre reciclagem e meio ambiente e agora eu tô aprendendo mais. Eu tinha até desistido de trabalhar, largado tudo. Aí a R. foi lá me buscar, me motivou, disse "O. quer que tu trabalhes com ele no caminhão", e aí eu vim e fui superbem recebido.

O trabalho é árduo e realizado de segunda a sexta-feira regularmente e, quando necessário, também aos sábados. A coleta nas ruas, com o caminhão, a triagem do material, a pesagem e o enfardamento são trabalhos intensos e o cansaço, perceptível.

Isso nos remete a Druck $(2011,2013)$ quando aponta que há uma nova precarização do trabalho que se constitui tanto econômica e social quanto politicamente, havendo uma institucionalização dos processos de flexibilização e da precarização modernas do trabalho, em especial, nos últimos 30 anos. Justificada pela necessidade de adaptação aos novos tempos globais, ela mantém, entretanto, uma visão hegemônica do capital e solidifica uma inevitabilidade e inexorabilidade de um processo mundial de precarização, também vivido de modo geral por todos os países desenvolvidos, embora de diferentes formas.

Esses são apenas alguns elementos que exemplificam a precariedade do trabalho e a condição vulnerável em que os trabalhadores da cooperativa se encontram. Esse cenário pode ser compreendido melhor com base nos estudos de Castel (2003), que afirma ser difícil estabelecer uma clara separação entre a precariedade e a vulnerabilidade, uma vez que ambas estão entrelaçadas. 
O interessante que emerge dos dados da pesquisa é que mesmo um trabalho estigmatizado e pesado pode ser via de reconhecimento no coletivo, fonte de aprendizagem e razão para ter esperança, caso se criem as condições institucionais para tanto. No caso da cooperativa investigada, mesmo com muitas dificuldades, o grupo pareceu estar engajado na criação dessas condições, articulando-se com a prefeitura municipal (para convênios) e a sociedade civil (escolas, empresas, órgãos públicos, moradias) para fornecimento de material pré-separado. Tais interações produzem efeitos sobre os sujeitos, que por meio delas se sentem parte de uma dinâmica social mais ampla.

\section{Categoria 2: Trabalho com o lixo - esperança e reconhecimento social}

Durante o processo de coleta de dados, as dificuldades dos entrevistados quanto à reinserção no mercado de trabalho ficaram evidentes. A certeza de que são e/ou serão rejeitados pelo mercado de trabalho formal fica clara em algumas falas selecionadas.

Eu vim por necessidade, eu vim porque estava passando fome. Era minha última opção. Antes eu trabalhei como assalariada por pouco tempo. Eu não ia conseguir novamente o trabalho nem sem, nem com carteira.

Não trabalhei mais e não consegui mais emprego. É difícil emprego comigo em função do preconceito, então a minha prima me falou daqui. Ela falou que é muito bom aqui na cooperativa. Vim aqui, falei com a coordenação e gostei. Falei com ela uma sextafeira e no sábado já trabalhei. Gosto muito daqui e não quero sair.

Os sujeitos entrevistados foram atingidos por essa condição e, portanto, em algum momento de suas vidas, perceberam-se fora dos "circuitos de trocas produtivas", tornando-se inúteis nos espaços socialmente aceitáveis, que se articulam pela interdependência funcional entre seus membros produtivos. O grupo, dessa forma, não apenas estava em uma condição de desfiliação, de flutuação dentro da estrutura social - em alguns casos, inclusive desfiliação sociofamiliar - mas igualmente estava de algum modo "separado" das esferas privilegiadas da sociedade por uma linha abissal (SANTOS, 2007), que fomentava nos sujeitos uma condição de vida repleta de desconfiança e insegurança, em razão de seu suposto status de inferioridade.

Contudo, esse mesmo cenário aponta uma expectativa do novo, que mesmo sendo contraditório traz esperança de melhoria de vida, de alguma mobilidade e aceitação social.

O lixo significa muito, muito, muito, muito mesmo, porque numa empresa, hoje, eles vão avaliar o currículo, como tu coloca o currículo, o que tu vai falar pra se expressar, aqui não. Aqui no lixo, a gente só o ouve "você quer trabalhar?" Se tu responde sim, tu trabalha. O lixo me modificou, me deu esperança de ser gente, e fez isto com vários aqui de dentro. Não é fácil trabalhar com o lixo, tem cheiro, tem preconceito, tem sujeira. Não era o que eu sonhava pra mim, mas agora que estou aqui ele me dá a esperança de dias melhores, me dá respeito. Acho que Deus me trouxe pro lixo, pra me salvar e salvar várias pessoas. Eles (Deus e o lixo) me transformaram (risos). Veja bem, o lixo é democrático, em especial na cooperativa, pois ela permite o pobre de dizer assim: "eu sou dono do meu negócio". O lixo mudou minha vida sim! O lixo deu mais dignidade para mim e futuro para os meus filhos. Me deu força para pensar e lutar, mas é difícil. Não é pra fraco não! O lixo me deu esperança de vida.

A noção de esperança, presente nas falas dos entrevistados, está ligada à ideia do depósito de uma expectativa, de uma promessa; contudo, a esperança aqui retratada é mais proativa, trata-se daquela que concede ao sujeito a ideia de que é capaz de fazer algo acontecer, de uma força que o lança a novos desafios e lhe dá a impressão de ser apto para alcançá-los. 
O DSC apresentou que, aliada à ideia de esperança e futuro, está a questão da dignidade. De diferentes formas, é um elemento comum nas narrativas dos trabalhadores, o que gera certa ordem social no interior da cooperativa. A construção e vivência da dignidade acabam sendo promovidas por meio de práticas cotidianas, estratégias de ação que podem ser muito diferentes entre si, mas que entrelaçam o acontecer do cotidiano.

\begin{abstract}
A gente vai trabalhando, juntos... temos esperança que se a gente trabalhar bem, comunicar com a comunidade, as pessoas vão entender a importância de reciclar, no futuro. Ainda pouca gente separa direitinho, entende a reciclagem. Mas eu antes de vir pra cá, eu também não sabia.

A gente conversa, se sente bem aqui... eu tive uma oportunidade, de ter trabalho, de sobreviver do trabalho da gente, de tirar o sustento daqui. Tem ainda a força do grupo C., é um grupo forte, é uma forma de vida e aqui eu tive várias experiências que eu jamais ia saber... A cooperativa leva a gente a conhecer as pessoas, cada um com sua opinião, antes eu era agressiva, ignorante, aqui a gente tem de olhar pro outro e perguntar “como tu estás?” então a gente fica mais digna. Que legal essa música, "no meio do caminho uma pedra... pareceu ser o caminho". Às vezes é isso aí, a pedra é o caminho, é pedreira, a vida é dura.
\end{abstract}

A dignidade humana reafirma a autoestima, possibilita aos sujeitos lutar para determinar seus caminhos de maneira que desenvolvam e vivenciem tanto a autonomia quanto a liberdade, bem como reconheçam tanto suas forças quanto suas limitações, o que se reflete, inclusive, na capacidade de interagir com os outros. A dignidade presente no grupo está vinculada não apenas à questão material que o trabalho tem proporcionado; trata-se antes de um princípio fundante de que toda pessoa humana é digna e merece oportunidade de trabalhar. Por meio dessa dignidade, surge a consciência de que todo ato que promova seu aviltamento atinge as expectativas construídas quanto ao futuro.

Ressalta-se que a estrutura do mercado de reciclagem não apresenta uma condição economicamente salutar, e que a situação de insegurança se perpetua - no grupo pesquisado, em especial pelo volume de resíduo coletado e comercializado -, fazendo com que ele se sinta em um círculo econômico um tanto incerto; contudo, suas redes de relações têm ajudado a limitar as incertezas e a ampliar a expectativas de futuro, especialmente por um ganho atingido que ultrapassou o valor do salário mínimo. Os ganhos são sazonais: quanto mais material de valor agregado, como alumínio, mais dinheiro recebem na hora da divisão das sobras do mês.

Para exemplificar mais uma ideia anteriormente apresentada, algumas falas merecem destaque: "quando eu olho o lixo na rua, eu penso que ele mudou a minha vida"; "o lixo me deu mais dignidade, mais conhecimento"; "o lixo me deu o luxo de ter dignidade". Aparentemente, o luxo da dignidade está alicerçado no ideal de ter um trabalho que faz os entrevistados se sentirem úteis, que vai além da satisfação das necessidades básicas. E, por mais simples que a atividade de reciclagem pareça aos olhos da sociedade, para eles essa atividade, atualmente, vem promovendo a dignificação de sua vida, oriunda da capacidade de, também, em algumas instâncias, promover o ser.

Vale destacar, igualmente, algumas ideias presentes nos discursos que apontam em direção ao que Maffesoli (1996) denomina de estética social. Para o autor, é na necessidade de pertencer que o laço social se constitui. Trata-se de uma potência que cria a solidariedade e favorece a fusão. Assim, percebeu-se que o convívio existente entre os sujeitos fomentou a partilha de emoções e sensações, um estar-junto detentor de uma força capaz de oportunizar participações mais ativas diante dos problemas enfrentados no cotidiano do trabalho. 
Nesse sentido, é importante entender o trabalho por meio de seu papel social - sem ser único nem imutável nem sempre central -, que ao longo da história da humanidade vem corroborando a constituição de identidades (múltiplas e inconstantes) dos sujeitos. Como esclarecem alguns entrevistados:

Trabalho é importante pra vida do ser humano, sabe? Ele não apenas nos oferece o dinheiro, mas a dignidade. Quem não trabalha não tem nada. Com o trabalho, a gente pode ser uma pessoa melhor. Não é fácil trabalhar no lixo, é pesado, é sujo e as pessoas olham torto, às vezes, mas ele nos oferece possibilidades.

Eu trabalho aqui e não preciso vender o corpo. Só quando eu quero. Sabe, trabalhar na noite não é bom. É ruim...

O espaço de trabalho, portanto, é mais um elemento que ajuda a clarear e compreender a tríade homem-lixo-trabalho. É um feixe de luz que contribui com sua tradução: a autoestima, o cuidado com o outro, a noção de igualdade e segurança constituem um lócus ético e estético que propicia uma (re)ligação por meio de uma óptica/ética da emoção da partilha de sentidos. Essa emoção, no entanto, não é um "simples fenômeno psicológico, ou um suplemento da alma sem consequência, é uma estrutura antropológica, cujos efeitos ainda estão aí para serem apreciados" (MAFFESOLI, 1996, p. 29). Ela conduz a um novo tipo de ligação com o outro que repousa na correspondência, no reconhecimento daquele que está próximo.

\section{CONSIDERAÇÕES FINAIS}

Por meio dos DSCs foi possível perceber o importante espaço que o trabalho associado ocupa na vida dos entrevistados. Suas representações emergentes, alicerçadas não apenas na dimensão econômica, mas nas sociabilidades que por meio da associação são vivenciadas mostraram, mais uma vez, as potencialidades presentes no campo da economia solidária. O trabalho com o lixo realizado cooperativamente traz não só a conquista e a manutenção de uma renda suficiente, mas igualmente sustenta relações subjetivas com o mundo, em uma perspectiva integradora. O trabalho torna-se assim uma ferramenta de (re)conquista da dignidade, colaborando para que esses sujeitos construam caminhos que contribuam para saírem da zona de desfiliação, ou seja: apesar do trabalho precário, percebe-se uma fragilidade relacional menor, minimizada pelo sustentáculo do coletivo.

Essa perspectiva, aparentemente percebida pelos entrevistados, traz certo sentido de esperança de melhorias na realidade de trabalho, ultrapassando a lógica de que essa é uma atividade provisória que se limita à sobrevivência. Existe uma esperança no interior do grupo pesquisado que o fortalece; de que, em médio prazo, estarão realizando uma atividade mais produtiva e socialmente reconhecida como relevante, propiciando um modo de viver a vida de forma reconhecidamente digna, para fora de seu círculo social imediato.

É necessário, contudo, sempre reconhecer as fragilidades que também compõem a constelação de forças na economia solidária. As condições estruturais adversas estão sempre colocando em cheque e ameaçando as realizações e conquistas, tanto materiais quanto subjetivas. Nesse sentido, percebe-se que uma frase de Ernst Bloch (2005) paira sobre os sujeitos: "junto a cada esperança, há sempre um caixão à espera". Isso porque há sempre a possibilidade da dissolução, ao lado da potencialidade de construção. A ambiguidade encontra-se presente e é percebida pelos sujeitos, compondo medos e recuos. Por mais que o trabalho seja interpretado pelo grupo como relevante, é inegável que os recicladores também percebam o significado negativo e estigmatizado que essa atividade ainda tem para boa parte da população - e, em 
algum momento, para eles próprios - e que acaba vinculada não apenas aos espaços dos rejeitos, mas às próprias pessoas que fazem dele a matéria-prima de suas atividades diárias.

A constelação representacional (JOVCHELOVITCH, 2008) é contraditória e apresenta ambiguidades, mas são perceptíveis os elementos agregadores e de transformação positiva das identidades - e são esses que foram escolhidos como dignos de nota e valorização.

Isso por acreditarmos que é importante destacar que representações oriundas do trabalho como dignidade, pertencimento e esperança se entrelaçam no cotidiano e podem se tornar combustível para um processo de inserção relacional mais forte e de politização da vida, resultando em novas relações estabelecidas, fortalecidas e compartilhadas. Realizações como a formação e condução de um movimento social nacional com ligações internacionais como o MNCR são, provavelmente, fruto desse tipo de esperança. É com base nesse ser mais fortalecido que a tríade sujeito-lixo-trabalho alcança seu sentido talvez mais relevante, uma esperança de ser mais por meio do trabalho.

Este estudo se debruçou sobre vidas humanas, com base em narrativas - e escutas repletas de expectativas e esperanças. É desse ser que o texto tratou, buscando compreender melhor quem são esses sujeitos que, a cada discurso expresso no âmbito coletivo da cooperativa, se revelaram um pouco, um pouco de cada vez. Finalizamos com uma citação que expressa nossa crença nas potencialidades do campo da economia solidária:

A esperança reside antes na possibilidade de criar campos de experimentação social onde seja possível resistir localmente às evidências da inevitabilidade [dos riscos], promovendo com êxito alternativas que parecem utópicas em todos os tempos e lugares, exceto naquelas em que ocorreram efetivamente (SANTOS, 1999, p. 214).

\section{REFERÊNCIAS}

ADICHIE, Chimamanda Ngozi. Os perigos de uma única história. Conferência Anual - TED GLOBAL 2009, 21-24 de julho, Oxford, Reino Unido. Disponível em: https://www.geledes. org.br/chimamanda-adichie-o-perigo-de-uma-unica-historia/. Acesso em: 6 maio 2020.

ALVAREZ, Raúl Nestór. O lixo como uma construção social. IHU On-line: Revista do Instituto Humanas Unisinos. n. 410, 3 dez. 2012. Disponível em http://www.ihuonline.unisinos.br/ artigo/4795-raul-nestor-alvarez. Acesso em: 6 maio 2020.

BAUER, Martin; GASKELL, George. Pesquisa qualitativa com texto, imagem e som: um manual prático. Petrópolis: Vozes, 2002.

BAUMAN, Zygmunt. Modernidade e ambivalência. Rio de Janeiro: Zahar, 1999.

Vidas desperdiçadas. Rio de Janeiro: Jorge Zahar, 2005.

BELFIORI-WANDERLEY, Luiz Eduardo. A questão social no contexto da globalização: o caso latino-americano e o caribenho. In: CASTEL, Robert et al. Desigualdade e a questão social. 3. ed. São Paulo: EDUC, 2011. p. 55-166.

BLOCH, Ernst. O princípio esperança. Tradução de Nélio Schneider e Werner Fucks. Rio de Janeiro: Contraponto, 2005.

BRASIL. Ministério do Trabalho. Classificação Brasileira de Ocupações: CBO. Brasília: MTE, SPPE, 2017. 
BRASIL. Projeto de Lei n. $^{\mathbf{0}}$ 6822/10. Regulamenta o exercício das profíssões de Catador de Materiais Recicláveis e de Reciclador de Papel. Disponível em: https://www.camara.leg.br/ proposicoes Web/fichadetramitacao?idProposicao=466351. Acesso em: 23 abr. 2020.

CABRAL, Sueli Maria. Territórios insólitos: o lixo, o trabalho e seus guardiões. 2015. 215 f. Tese (Doutorado em Ciências Sociais) - Universidade do Vale do Rio dos Sinos, São Leopoldo, 2015.

CASTEL, Robert. Da indigência à exclusão, a desfiliação: precariedade do trabalho e vulnerabilidade relacional. In: LANCETTI, Antonio. Saúde Loucura. São Paulo: Hucitec, 1994. v. 4.

. A dinâmica dos processos de marginalização: da vulnerabilidade à "desfiliação". Caderno CRH, Salvador, v. 10, n. 26, p. 19-40, 1997.

As metamorfoses da questão social: uma crônica do salário. Petrópolis: Vozes, 2003.

CORBIN, A. Saberes e odores: o olfato e o imaginário social nos séculos dezoito e dezenove. São Paulo: Companhia das Letras, 1987.

DRUCK, Graça. A precarização social do trabalho no Brasil. In: ANTUNES, Ricardo. Riqueza e miséria do trabalho no Brasil II. São Paulo: Boitempo, 2013, p. 55-74.

. Trabalho, precarização e resistências: novos e velhos desafios? Caderno CRH, Salvador, v. 24, n. esp. 1, p. 35-55, 2011.

EIGENHEER, Emílio Maciel. Lixo, vanitas e morte. Niterói: EdUFF, 2003.

FREITAG, Barbara. Teorias da cidade. Campinas: Papirus, 2007.

GAIGER, Luiz Inácio Germany. A economia solidária no Brasil: uma análise dos dados nacionais. São Leopoldo: Oikos, 2014.

GAIGER, Luiz Inácio Germany; KUYVEN, Patrícia Sorgatto. Economia solidária e trajetórias de trabalho: uma visão retrospectiva a partir de dados nacionais. Rev. Bras. Ci. Soc., São Paulo, v. 35, n. 103, 2020.

GIDDENS, Anthony. Sociologia. 6. ed. Porto Alegre: Penso, 2012.

IBGE - INSTITUTO BRASILEIRO DE GEOGRAFIA E ESTATÍSTICA. Pesquisa Nacional por Amostra de Domicílio, 2017. Disponível em: https://www.ibge.gov.br/estatisticas/sociais/ trabalho/2067-np-pesquisa-nacional-por-amostra-de-domicilios-continua/9171-pesquisanacional-por-amostra-de-domicilios-continua-mensal.html $?=\& \mathrm{t}=$ destaques. Acesso em: 20 mar. 2020.

IPEA - INSTITUTO DE PESQUISA ECONÔMICAAPLICADA. Situação social das catadoras e dos catadores de material reciclável e reutilizável. 2013. Disponível em: https://www.ipea. gov.br/portal/index.php?option=com_content\&view $=$ article\&id=20986\&Itemid=9. Acesso em: 15 maio 2020.

IPEA - INSTITUTO DE PESQUISA ECONÔMICA APLICADA. A organização coletiva de catadores de material reciclável no brasil: dilemas e potencialidades sob a ótica da economia solidária. Cadernos de Estudos, 2017. Disponível em http://repositorio.ipea.gov.br/ bitstream/11058/7413/1/td_2268.PDF. Acesso em: 6 maio 2020.

JOVCHELOVITCH, Sandra. Os contextos do saber: representações, comunidade e cultura. Petrópolis: Vozes, 2008. 
KUYVEN, Patrícia. Economia solidária no Brasil: uma alternativa para redução da pobreza através da geração de renda. 2016. Tese (Doutorado em Ciências Sociais) - Universidade do Vale do Rio dos Sinos (Unisinos), São Leopoldo, 2016.

LACERDA, Luiz Felipe Barbosa. Governar-se para quê? As práticas de gestão dos empreendimentos econômicos solidários. Porto Alegre: EDIPUCRS, 2013.

LEFEVRE, Fernando; LEFEVRE, Ana Maria Cavalcanti; TEIXEIRA, Jorge Juarez Vieira. O discurso do sujeito coletivo: uma nova abordagem metodológica em pesquisa qualitativa. Caxias do Sul: EDUCS, 2000.

LEFEVRE, Ana Maria Cavalcanti; CRESTANA, Maria Fazanelli,; CORNETTA, Vitória Kédy. A utilização da metodologia do discurso do sujeito coletivo na avaliação qualitativa dos cursos de especialização "Capacitação e Desenvolvimento de Recursos Humanos em SaúdeCADRHU”, São Paulo - 2002. Saúde e Sociedade, v. 12, n. 2, p. 68-75, 2003. Disponível em: https://dx.doi.org/10.1590/S0104-12902003000200007. Acesso em: dez. 2019.

MAFFESOLI, Michael. No fundo das aparências. Petrópolis: Vozes, 1996.

MNCR - MOVIMENTO NACIONAL DOS CATADORES DE MATERIAIS RECICLÁVEIS. Quantos catadores existem em atividade no Brasil?. 2019. Disponível em http://www. mncr.org.br/sobre-o-mncr/duvidas-frequentes/quantos-catadores-existem-em-atividade-nobrasil\#: : text=A\%20estimativa $\% 20$ do $\% 20 \mathrm{MNCR} \% 20 \% \mathrm{C} 3 \% \mathrm{~A} 9, \% \mathrm{C} 3 \% \mathrm{~A} 9 \% 20$ reciclado $\% 20$ hoje\%20no\%20Brasil. Acesso em: 5 maio 2020.

MOSCOVICI, Serge. Representações sociais: investigações em Psicologia Social. Petrópolis: Vozes, 2009.

OLIVEIRA, Gustavo; VERONESE, Marilia Verissimo. Brasil y el "fenómeno Bolsonaro": un análisis preliminar. Revista Mexicana de Ciencias Políticas y Sociales, v. 64, n. 237, ago. 2019. Disponível em: http://www.revistas.unam.mx/index.php/rmcpys/article/view/68273. Acesso em: 31 maio 2020. DOI: http://dx.doi.org/10.22201/fcpys.2448492xe.2019.237.68273.

PAUGAM, S. Desqualificação social: ensaio sobre a nova pobreza. Tradução de Camila Giorgetti e Tereza Lourenço. São Paulo: Educ \& Cortez, 2003.

SANTANA, L.; DOURADO, D. A criação dos Programas de Transferência de Renda e a Precarização do Trabalho no século XXI: A emancipação dos beneficiários do Programa Bolsa Família é possível? Revista Brasileira de Políticas Públicas e Internacionais, v. 3, n. 2, 2018, p. $125-151$.

SANTOS, Boaventura Santos. Para além do pensamento abissal: das linhas globais a uma ecologia de saberes. Novos Estudos - CEBRAP, n. 79, p. 71-94, nov. 2007. Disponível em: https://dx.doi.org/10.1590/S0101-33002007000300004. Acesso em: 10 abr. 2013.

Porque é tão difícil construir uma teoria crítica? Revista Crítica de Ciências Sociais, Coimbra, v. 54, p. 197-215, 1999.

SEN, Amartya. Desenvolvimento como liberdade. São Paulo: Cia das Letras, 2000.

SENAES - SECRETARIA NACIONAL DE ECONOMIA SOLIDÁRIA. Atlas Digital da Economia Solidária. Dados do Segundo Mapeamento Nacional de Empreendimentos Econômicos Solidários (EES), 2013. Disponível em: http://atlas.sies.org.br/sobre. html\#: : text=Esta $\% 20$ Base $\% 20 \mathrm{de} \% 20 \mathrm{Dados} \% 20 \% \mathrm{C} 3 \% \mathrm{~A} 9$, conta $\% 20$ atualmente $\% 20$ 19.708\%20EES\%20registrados. Acesso em: 2 maio 2020. 
SILVA, Ari Rocha da. O ser e o estar catador: experiências sociais no trabalho e nas tramas urbanas. 2018. Tese (Doutorado em Ciências Sociais) - Universidade do Vale do Rio dos Sinos Unisinos, São Leopoldo, 2018.

SILVA, Sandro Pereira; CARNEIRO, Leandro Marcondes. Empreendimentos de economia solidária na cadeia produtiva da reciclagem: um olhar inicial sobre os dados do sistema de informações da economia solidária. Mercado de Trabalho, n. 59, ano 21, out. 2015.

SOUZA, Jessé. A elite do atraso. Rio de Janeiro: Leya, 2017.

VERONESE, Marilia Verissimo. Associativismo entre catadores de material reciclável urbano. Contemporânea, v. 6, n. 1, p. 125-151, 2016.

VERONESE, Marilia Verissimo; GAIGER, Luiz; FERRARINI, Adriane. Sobre a diversidade de formatos e atores sociais no campo da economia solidária. Caderno CRH, Salvador, v. 30, n. 79, p. 89-104, 2017.

VERONESE, Marilia Verissimo; SCHOLZ, Robinson. A difícil construção da liderança solidária compartilhada. Século XXI: Revista de Ciências Sociais, v. 3, n. 2, p. 41-64, jan. 2014. Disponível em: https://periodicos.ufsm.br/seculoxxi/article/view/12792. Acesso em: 31 maio 2020. DOI: http://dx.doi.org/10.5902/2236672512792.

Recebido em: 02/06/2020

Aceito para publicação em: 30/11/2020 